\title{
Hyperparasitism of Homona coffearia Nietn. (Lepidoptera: Tortricidae), the Tea Tortrix of Sri Lanka: Implications for Biological Control
}

\author{
Ravindra S. Walgama \\ Division of Entomology, Tea Research Institute, Talawakelle, Sri Lanka \\ Email: sampathwalgama@hotmail.com
}

Received 28 February 2015; accepted 26 March 2015; published 2 April 2015

Copyright (C) 2015 by author and Scientific Research Publishing Inc.

This work is licensed under the Creative Commons Attribution International License (CC BY). http://creativecommons.org/licenses/by/4.0/

(c) (†) Open Access

\begin{abstract}
Tea tortrix, Homona coffearia Nietner (Lepidoptera: Tortricidae), is a seasonal pest of tea in Sri Lanka. Though it is active in dry weather, it is observed that populations do occur in wet weather causing serious damage to tea. The parasite, Macrocentrus homonae Nixon (Hymenoptera: Braconidae), controls the tortrix populations, but the efficiency of Macrocentrus has been reduced on account of hyperparasites in recent times. Level of hyperparasitism was studied in some tea tortrix prone areas in the up country region to study how this affected the tortrix populations during wet weather. The hyperparasitism varied during the study period of which average values observed ranged from $35 \%$ to $52 \%$ in the plantations studied. A negative linear relationship was observed between the average number of parasite cocoons in a cocoon mass and the percentage hyperparasitism. Three generations of tortrix were evident during the study period of May to November 2005. It is observed that tortrix populations do occur in dry and wet weather, and that hyperparasitism has been identified as the major cause affecting the efficient control of tortrix by the parasite. Possibilities of tea tortrix control in wet weather are discussed.
\end{abstract}

\section{Keywords}

Control, Hyperparasitism, Homona coffearia, Lepidoptera, Macrocentrus homonae, Parasites, Tea Tortrix, Tea Plantation

\section{Introduction}

Tea Camellia sinensis (O Kuntz) is a perennial tree crop grown intensively on a very large acreage. Unlike an

How to cite this paper: Walgama, R.S. (2015) Hyperparasitism of Homona coffearia Nietn. (Lepidoptera: Tortricidae), the Tea Tortrix of Sri Lanka: Implications for Biological Control. Advances in Entomology, 3, 33-43. 
annual crop, a long lived tree crop exists for a long period of time on the same ground to build up a balanced community of insects and other organisms. Also, tea in Sri Lanka provides an ecosystem where the general balance of organisms can easily be maintained and therefore, a system where biological control can play a major role in the management of phytophagous insects.

Tea tortrix, Homona coffearia Nietner (Lepidoptera: Tortricidae), is an important pest of tea in Sri Lanka. Pest incidences are frequently reported from Dimbula, Upper Dickoya, Maskeliya, Uda Pussellawa and Pundalu Oya areas in the up country (elevation $>1200 \mathrm{~m}$ a.s.l) and Welimada, Badulla and Passara areas in the mid country dry region (elevation 600 - $1200 \mathrm{~m}$ a.s.l). About 25 native insect parasites have been recorded to attack $H$. coffearia, but none of those have given adequate control over the populations [1]. A larval parasite, Macrocentrus homonae Nixon. (Hymenoptera: Braconidae), was introduced as a biological control agent of $H$. coffearia in Sri Lanka from Java in 1935. The introduction turned out to be an instant success with the parasite finding local conditions to its liking. Tea tortrix has been recorded as a minor pest of tea from the time its' exotic parasite, and $M$. homonae has been introduced as the latter spread at the expense of tea tortrix. Since then, tea tortrix was on a stable relationship with its density dependent parasitic wasp [2]. Macrocentrus was an efficient parasite due to its host specificity (tortrix is the only known host for Macrocentrus), its high searching capacity, high migratory power and polyembryony [3]. It was predicted that time might modify the initial efficacy of M. homonae as a control agent [4] [5]. The efficiency of M. homonae did in fact reduce on account of other parasites ("hyperparasites") which adopted M. homonae itself as their host. The local parasitic hymenopterans seemed to have recognized the new comer as soon as it was introduced [3].

Four hymenopteran species parasitizing which had been found to be able to parasitize $M$. homonae were identified as Ceraphron fijiensis (Hymenoptera: Braconidae), Apanteles spp. (Hymenoptera: Braconidae), Fornicia spp. (Hymenoptera: Braconidae) and Tetrastichus krishnieri (Hymenoptera: Euploididae) [4] [6]-[8]. Gadd [9] [10] found that $M$. homonae had temporarily lost its ability to control tea tortrix and that outbreaks of tea tortrix had been reported in both dry and wet weathers, though tea tortrix was considered as a pest active in dry weather. Hyperparasitism on the parasite of tea tortrix, Macrocentrus, had been a key factor that was considered to govern the population regulation of the pest, tea tortrix and its parasite [4] [6].

This study was done over a period of 6 months in 2005 and reported the situation in relation to the level of hyperparasitism in some locations (represented by tea plantations which were locally called as tea estates) in the up country region (Lindula and Pundalu Oya areas), which were known to have recurrent tortrix infestations in the past.

\section{Materials and Methods}

\subsection{Sampling}

The sampling locations of this study were 3 plantations: 1) Eildon Hall, 2) Duncinan and 3) Sheen estates in the up country region (elevation $\sim 1350 \mathrm{~m}$ a.s.l). These locations were selected, which were known to have a history of high tea tortrix infestations.

In each location, a field with prominent tea tortrix attack was selected for sampling. The superintendents of these plantations were consulted to find out best fields for such sampling. Twenty bushes were randomly sampled from the tortrix attacked areas by walking " $Z$ " manner and collected all the damaged leaves and tortrix nests. These bulk samples were collected into cloth bags and the locations were lableed before its being brought to the laboratory. Sampling was carried out weekly from June to November 2005.

\subsection{Sorting and Recording}

From each location laboratory samples were were sorted out separately and the following information was re corded.

1) Number of tortrix larvae-The number of larvae were categorized into three groups viz. proportions of these are small (if $<1.0 \mathrm{~cm}$ ), medium (if between 1 and $2.0 \mathrm{~cm}$ (medium) and large (if $>2.0 \mathrm{~cm}$ ).

The caterpillars were maintained in the laboratory on fresh tea shoots placed in beakers, filled with water (Figure 1(a)). The temperature of the laboratory was fluctuated around $25{ }^{\circ} \mathrm{C}$ while relative humidity was $75 \%$ during the rearing period. The tea shoots were replaced with fresh shoots as and when necessary. Observations were taken on the fate of the caterpillars. The caterpillars already parasitized by Macrocentrus, at the time of 


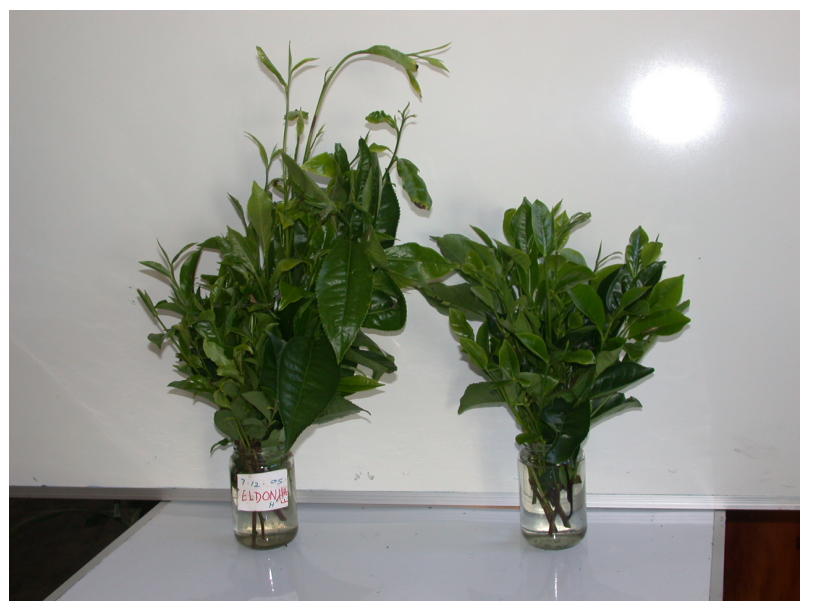

(a)

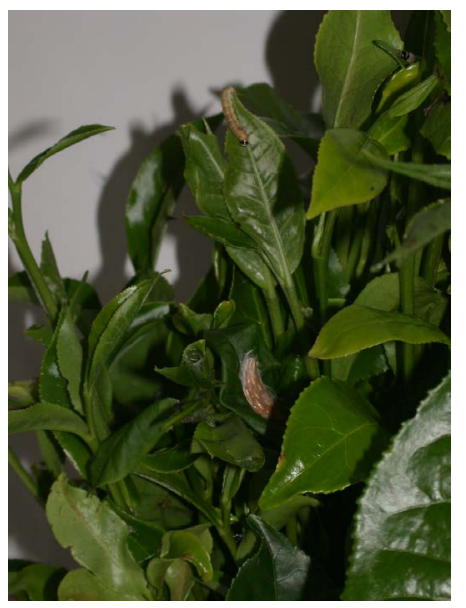

(b)

Figure 1. The tea shoots maintained in the laboratory to rear tortrix caterpillars (a) and the caterpillar and a Macrocentrus cocoon mass on a tea shoot (tea variety used in this experiment is TRI 2025) (b).

collecting, formed Macrocentrus cocoons (Figure 1(b)) and those were not, completed the life cycle to emerge as adult tortrix moths.

2) Number of fresh (Figure 2) and emerged Macrocentrus cocoon masses (either parasites emerged successfully or hyperparasites emerged) at the time of field collection and then reared in the laboratory.

a) Emergence of parasites was identified by the presence of an operculum at one end of the cocoon (Figure 3(a)).

b) Emergence of hyperparasites was identified by the circular hole on the cocoon (Figure 3(b)).

3) Number of cocoons in individual masses formed from the caterpillars reared in tea shoots in the laboratory, as described in 1 above. From observations 2 (both $\mathrm{a}$ and $\mathrm{b}$ ) and 3 the following parameters were calculated

a) Percent successful emergence of the parasite (number of successfully emerged cocoons/total number of cocoons) $\times 100$.

b) Percentage hyperparasitism (number of cocoons parasitized/total number of cocoons) $\times 100$.

\subsection{Statistical Analysis}

The analysis was performed using SAS user's manual, version 9.3 ed (2011) [11] where PROC TTEST was used to determine 1) the difference between the number of cocoons formed in laboratory reared caterpilars and the cocoons directly picked up from the field and 2) successful emergence of parasites from laboratory reared caterpillars and the field collected cocoons. Correlation analysis was used to determine the relationship between number of cocoons per cocoon mass and the \% hyperparasitism.

\section{Results}

Three generations of tea tortrix were identified during the period sampling was carried out in all locations, out of which population and abundance in two tea plantations are shown below (Figure 4(a) and Figure 4(b)). These generations are some of the characteristic 6-generation profile of tea tortrix in tea plantations in the upper elevations though timing of peak abundance varied across locations. The 1st, 2nd and 3rd generation peaks occurred around early July, mid-August and late October, respectively in Sheen tea estate while those of Duncinan estate occurred around mid-June, late August and mid-October, respectively. Sampling also showed that an time there is a mixture of caterpillars representing different size categories indicating overlapping generations and this may implicates control (Figure 5).

Results showed that some generations do occur in dry periods while others occur in wet periods. The 1st and the 3rd tortrix generations at Sheen estate coincided with the wet weather while the 2nd generation did occur in dry period (Figure 6). The 1st generation which is smaller in magnitude coincided with wet weather but the 3rd generation was high in magnitude also occurred in wet weather. This trend of populations occurring in wetter periods is frequently observed in recent times in plantations in upper elevations. The generation peaks occur roughly in 2 months intervals. 


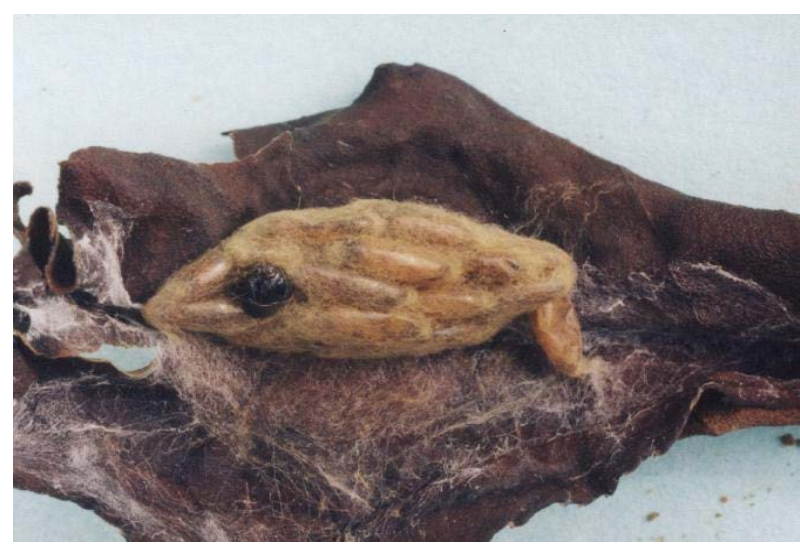

Figure 2. A Macrocentrus cocoon mass where cigar shaped individual pupal cocoons tightly affixed together (note the black shiny spot which was remains of the head of the tortrix caterpillar parasitized).

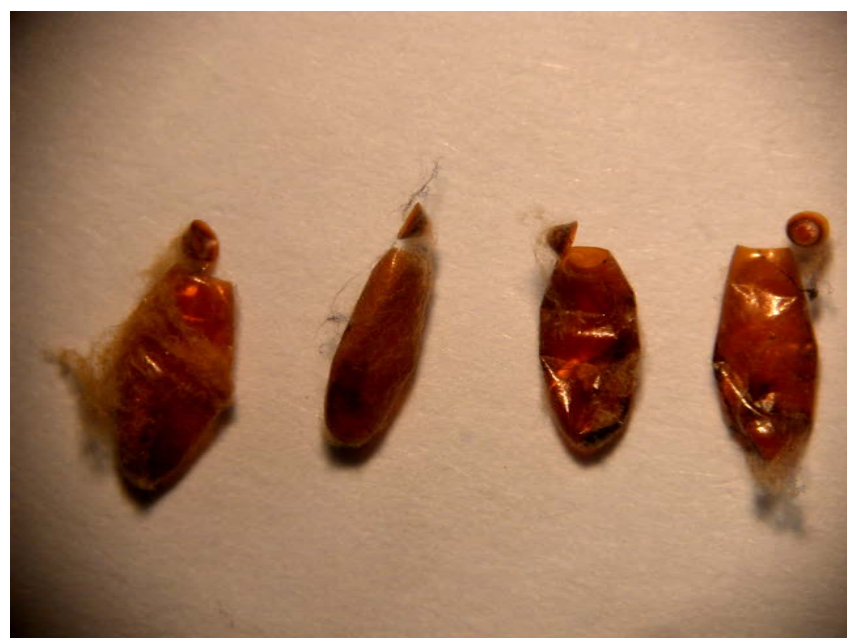

(a)

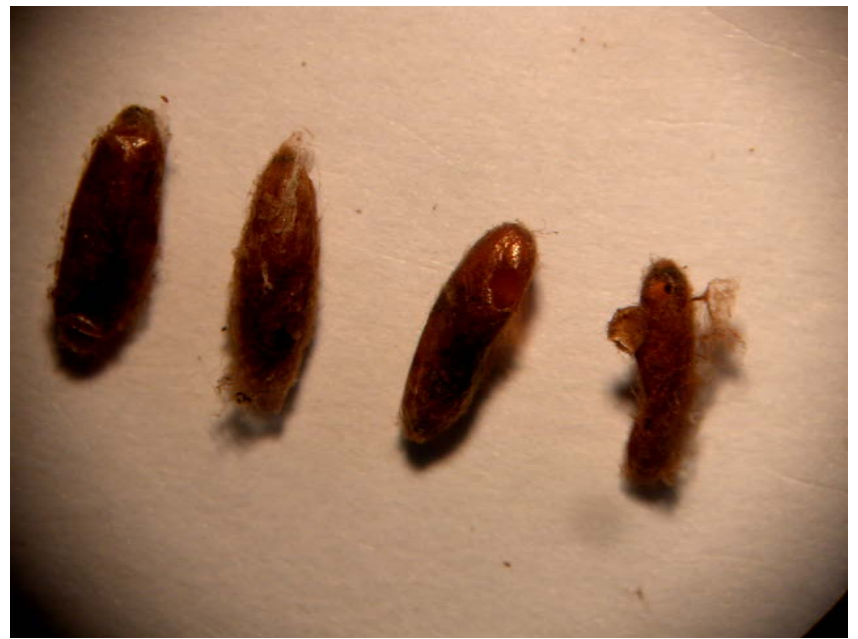

(b)

Figure 3. Macrocentrus cocoons showing signs of successful emergence (a) (note the operculum at the top end where Macrocentrus made its way out) and Macrocentrus cocoons showing signs of hyperparasite damage (b) (note the circular exit hole made by the hyperparasite). 


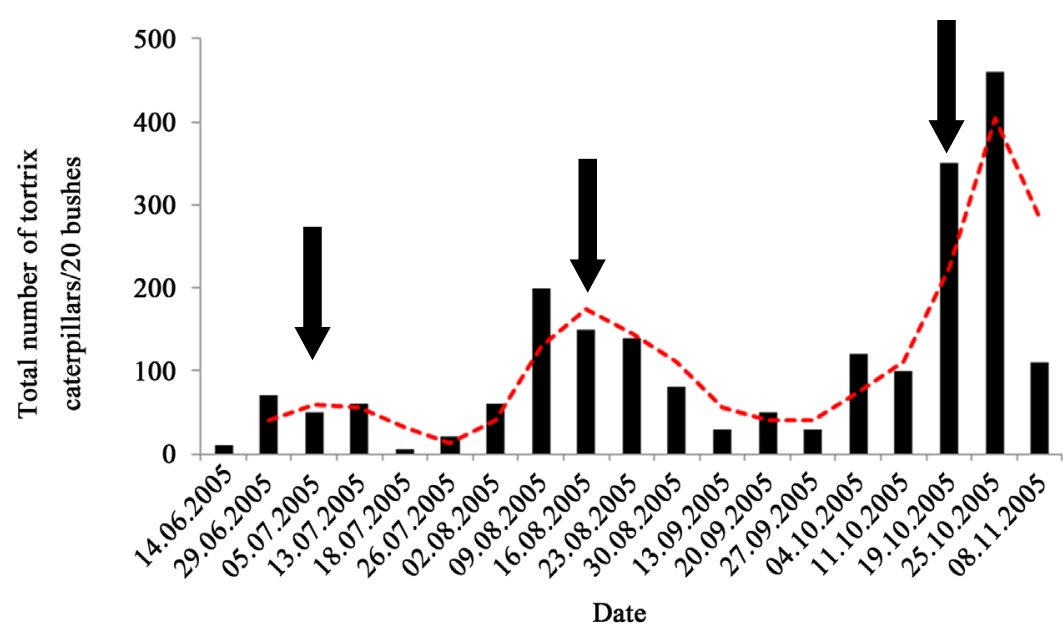

(a)

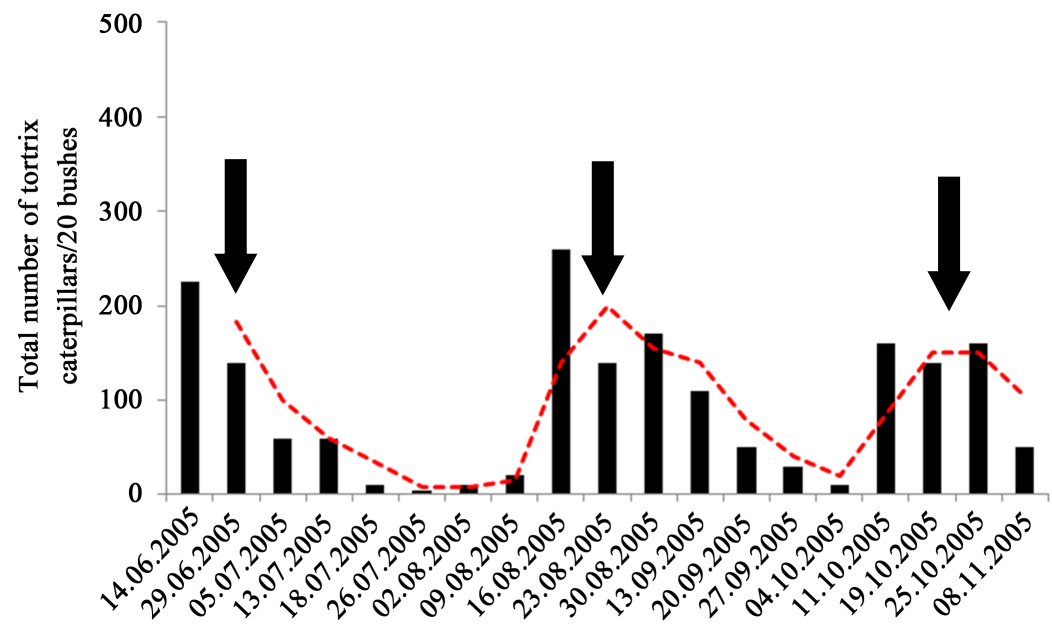

(b)

Figure 4. Population numbers of tea totrix over the sampling period; data from (a) Sheen estate and $(b)$ Duncinan estate (a moving average $(n=2)$ was included to highlighted the peaks which are indicated by arrows).

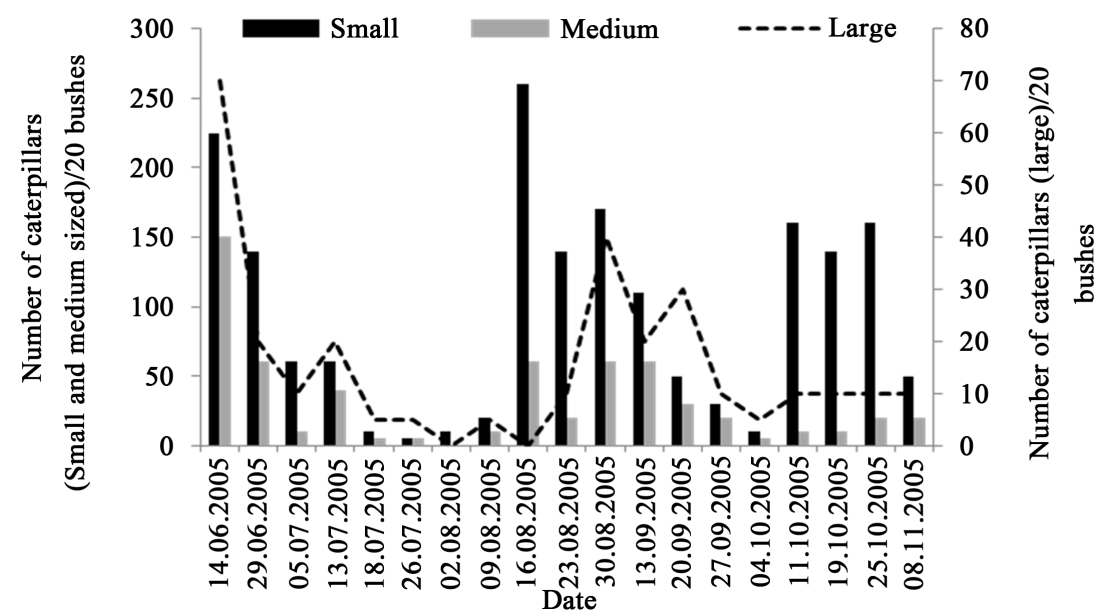

Figure 5. Appearance of larval stages of tea totrix over the sampling period; data from Duncinan estate. 


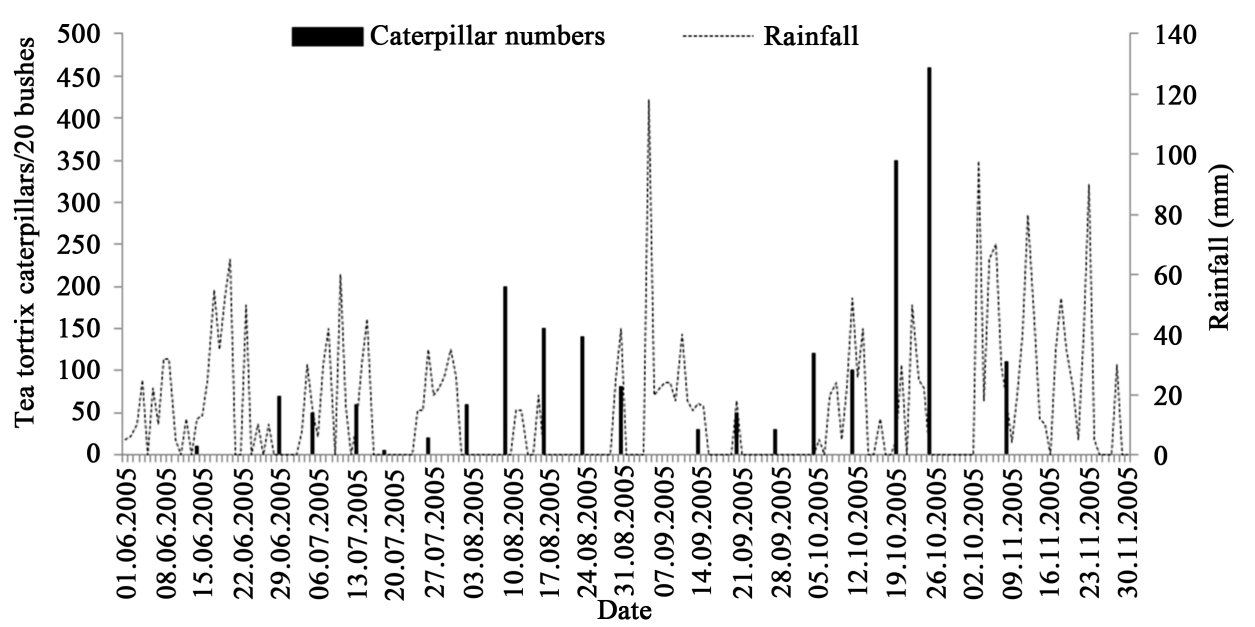

Figure 6. Population numbers of tea totrix in relation to rainfall over the sampling period; data from Sheen estate.

Results showed that hyperparasitism does occur in tea plantations in upper elevations where tea tortrix infestations are recurrent, i.e. Endemic. The hyperparasitism levels (expressed as \% hyperparasitism), on average, observed to be $35 \%$ (range $20 \%-50 \%$ ) in Eildon Hall, $43 \%(10 \%-90 \%)$ in Duncinan Estate and $52 \%(28 \%$ $100 \%$ ) in Sheen Estate but, it varied over the sampling period in each weather (Figure 7). Hyperparasitism is not common in Eildon Hall estate (Figure 7(c)) and Fernlands estate (data not shown) but it's commonly occurred in Sheen (Figure 7(a)) and Duncinan estates (Figure 7(b)). Though there was no such clear trend observed in this study, hyperparasitism was common during the wet periods than dry periods as shown in hyperparasitism levels at Sheen (Figure 7(a)) and Duncinan estate (Figure 7(b)).

The number of successfully emerged Macrocentrus parasites from the parasitized caterpillars reared in the laboratory till their emergence was significantly different compared to those emerged from the field collected cocoon masses incubated in the laboratory (Figures 8(a)-(c)) (PROC TTEST:, $\mathrm{df}=33, \mathrm{~F}=6.59, \mathrm{P}<0.0001$, SAS v.9.3, 2011). The successful emergence of parasites from the field collected caterpillars was on average $86 \%, 93 \%$ and $94 \%$ at Sheen, Duncinan and Eildon Hall estates respectively. Direct comparison of successfully emerged numbers from the field caterpillars and the field collected cocoons from Sheen estate show that it was on average $86 \%$ and $33 \%$, respectively (Figure $8(\mathrm{~d})$ ). The caterpillars collected from the field which had produced Macrocentrus cocoons in the laboratory, would have been parasitized when in the field. The high emergence rates of Macrocentrus from laboratory reared caterpillars would have been due to the fact that they have not been subjected to the ravages of hyperparasites. On the other hand, very low emergence of Macrocentrus from the field collected cocoons could be due to the fact that those cocoons would have been parasitized by hyperparasites at the time of field collection.

Results revealed that, there is a significant difference in the number of hyperparasitised pupal cocoons per mass, formed from the individual parasitized masses obtained from the laboratory reared tea tortrix caterpillars compared to those from the cocoon masses obtained directly from the field (Figure 9) (PROC TTEST, $\mathrm{df}=15$, $\mathrm{F}=5.68, \mathrm{P}=0.027$, SAS v.9.3, 2011). This was prominent in the samples collected from Sheen estate. The average number of cocoons formed in caterpillars reared in the laboratory and cocoons collected from field was 19 (range 12 - 32) and 14 (range 12 - 30) per mass, respectively. This would have been a result of parasitized caterpillars being reared in the laboratory till it develops into Macrocentrus cocoons, without encountering adverse conditions and impact on their development. The average number and the range of 12 - 32 cooons per mass found in this study were in line with the findings by Amarasinghe [12] that there were on average 22 pupal cocoons per mass.

It was also observed that there was a negative liner relationship between percent $\%$ hyperparasitism and the average number of $M$. homonae cocoons per cocoon mass $(y=-4823 \mathrm{x}+143.7$, where $\mathrm{y}=\%$ hyperparasitism and $\mathrm{x}=$ average number of cocoons per mass) (PROC CORREL: $\mathrm{r}=0.89, \mathrm{P}<0.00033$, SAS v.9.3, 2011) (Figure 10). This would be due to hyperparasites inability to attack individual cocoons when they are clumped more tightly into a compact mass. 


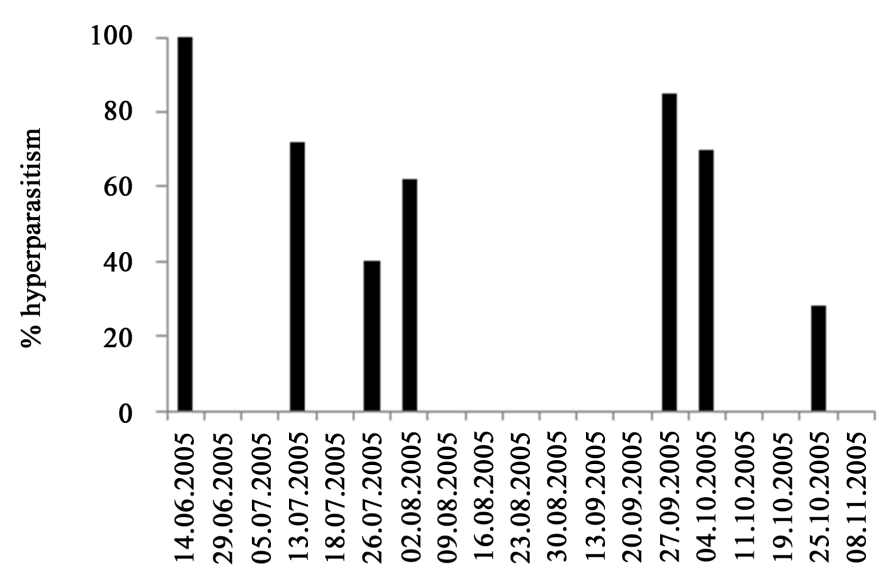

Date

(a)

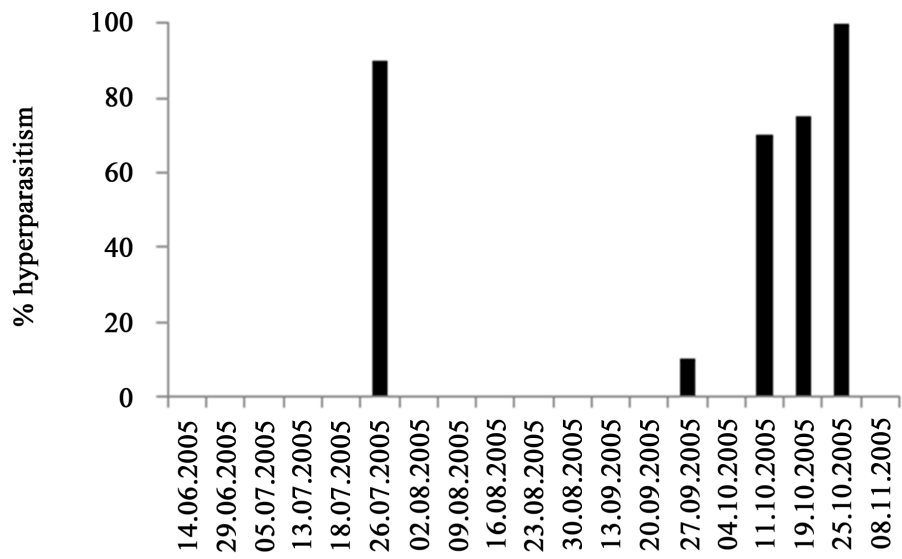

Date

(b)

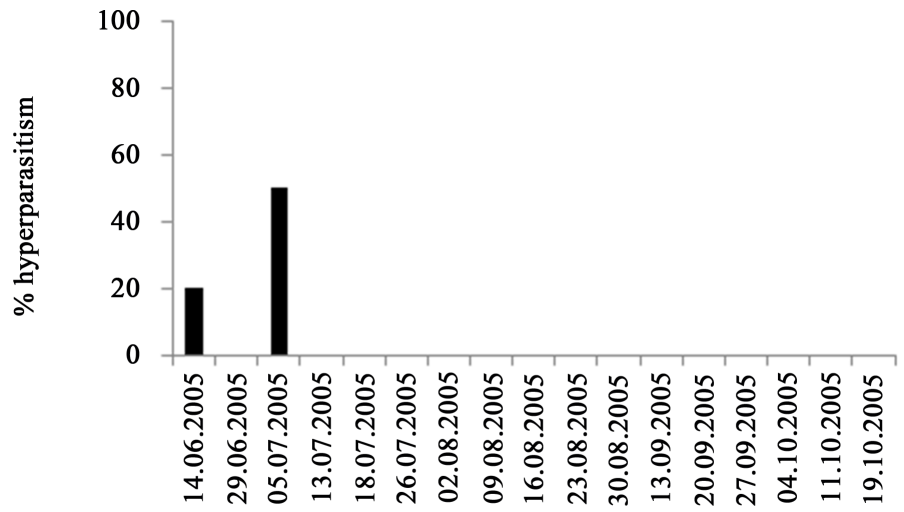

Date

(c)

Figure 7. Changes in Percentage hyperparasitism over the study period in the three estates sampled (a) Sheen estate, (b) Duncinan estate and (c) Eildon Hall estate (data from field collected cocoon masses). 


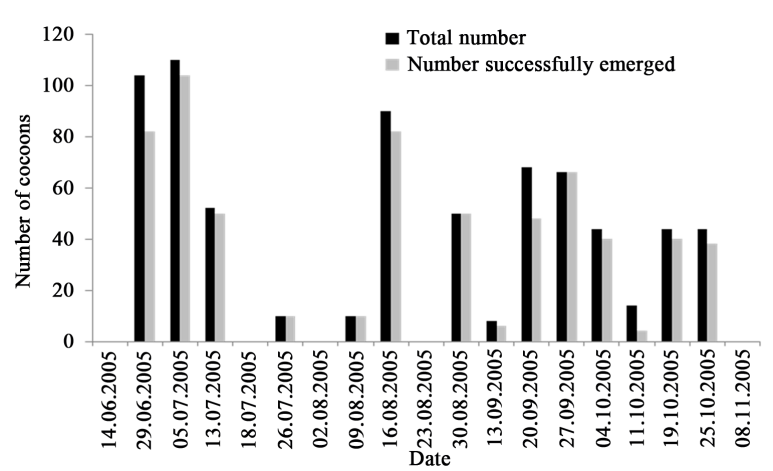

(a)

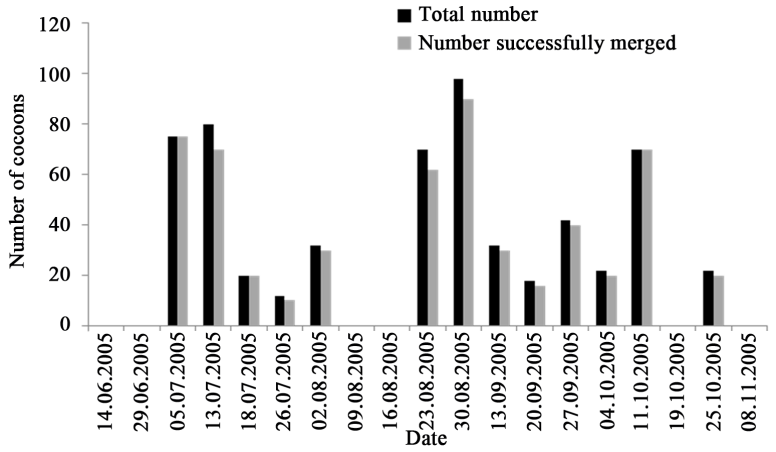

(b)

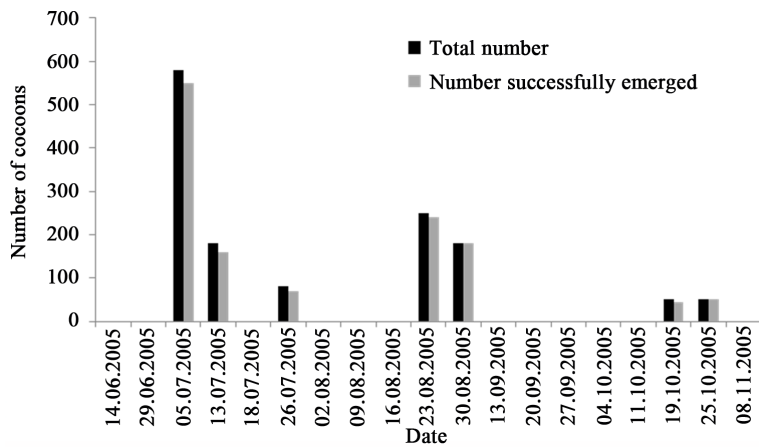

(c)

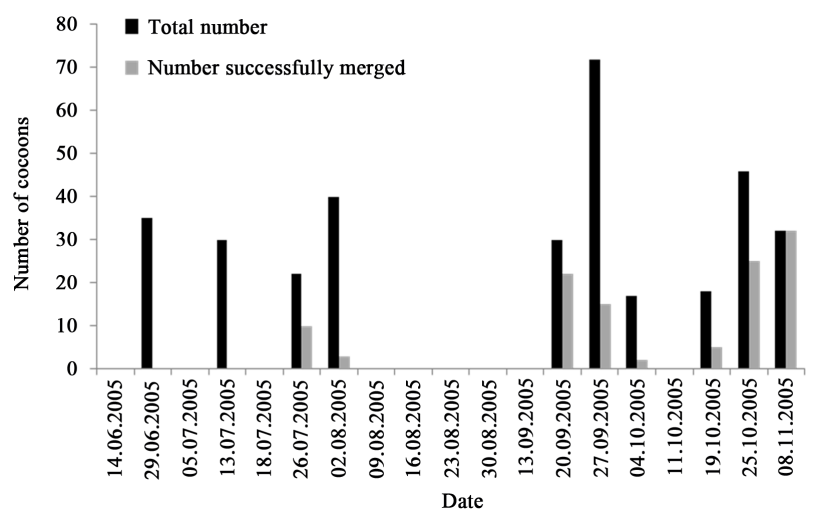

(d)

Figure 8. Successful emergence of Macrocentrus from laboratory reared tortrix caterpillars (a) Sheen estate; (b) Duncinan estate and (c) Eildon Hall samples and (d) field collected cocoons from Sheen state. 


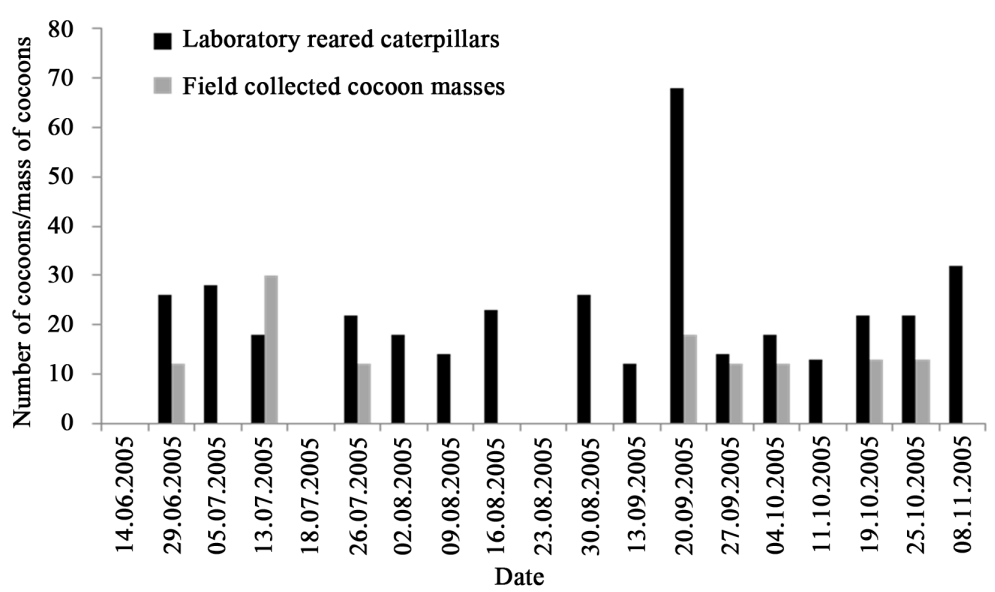

Figure 9. Differences in the number of cocoons formed from the caterpillars reared in the laboratory and the cocoon masses collected in the field (data from Sheen estate).

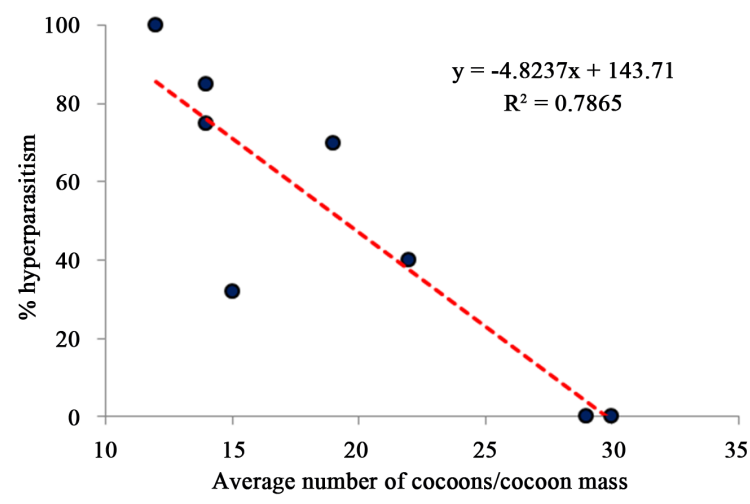

Figure 10. Relationship between \% hyperparasitism and the average number of cocoons per mass; samples from Sheen estate were used to derive this as Sheen estate did record more hyperparasite activity.

\section{Discussion}

This study provides some useful information on the occurrence of hyperparasitism in selected tea plantations in the upper elevations of the country. An earlier study has showed that different levels of hyperparasitism can range from $30 \%$ to $38 \%$ [12] [13], but the present study shows that the hyperparasitism will occur in much higher value of about $52 \%$ on average. High hyperparasitism levels were also observed in some occasions which could go about $100 \%$. The reason may be due to the lower hyperparasite efficacy of Macrocentrus on controlling tea tortrix. A study carried out in 1999 in another location where tea tortrix problem was endemic revealed that hyperparasitism level was 33\% and along with the effect of diseases on the cocoons of Macrocentrus (17\%), the unsuccessful emergence was totalled to $50 \%$, which resulted in successful emergence of Macrocentrus being $50 \%$ [12]. The higher number of successful emergence of Macrocentrus parasites in cocoons formed in parasitised caterpillars reared in laboratory than the successful emergence observed in the field is an indication that hyperparasitism is the main factor causing reduced efficiency of Macrocentrus in controlling tea tortrix.

The higher number of cocoons formed in the caterpillars reared in the laboratory compared with the numbers formed in field collected cocoons is interesting, which tells the fact that caterpillars in the laboratory are not exposed to adverse environmental conditions or impacts of human activities (harvesting, sprays, etc.) and allow development of full complement of Macrocentrus eggs compared with the caterpillars exposed to environment. This difference of average number of cocoons formed in two different environments can be attributed to the conditions under which the formation of cocoons has taken place. The average number of cocoons per mass of cocoon ranged from 17.2 to 23 recorded in this study is in line with the value recorded previously [12] which is 
22. This study also reports that the number of cocoons formed in a single mass can range from 11 to 68 ; values of more than 45 are not reported previously. This extremely high number of cocoons would have resulted from 2 parasitized caterpillars developed together which could be a rare instance. When the number of cocoons per mass is high, more numbers of parasites are available for controlling tea tortrix. At the same time, it is also noted that the higher the number of cocoons per mass of cocoons is, the lower the incidence of hyperparasitism is, which is new information obtained in this study. When the cocoon mass contains more cocoons and hence, becomes compact, the hyperparasites cannot attack the cocoons efficiently.

Though, tea tortrix considered as a pest in dry weather there were instances in recent times, where tortrix numbers have seen in wet weather too, which causes lots of concerns in plantations especially in the up country area. This is reflected in the study where high caterpillar numbers were observed in periods when high rainfall was also observed. The period of mid/late October was generally wetter and during this period the third populations (generation peak) were also observed. Therefore, this shows that tortrix populations can occur during the wetter periods as well, in addition to the drier periods where tortrix populations were supposed to occur.

High levels of parasitism of tea tortrix were observed over the years (1988-2000) which was ranged from 75\% $95 \%$ in many of the plantations in the upper elevations [12]. In a study carried out in one of the tea plantations in 2002, the parasitism level was greatly reduced to about $50 \%$ due mainly by hyperparasitism (about $33 \%$ ) and the diseases (about 17\%) [13]. Despite the fact that there are high levels of parasitism observed over the years, hyperparasitism affected the efficiency of Macrocentrus, the parasite of tea tortrix. Reduction in parasitism in recent times and the resultant frequent appearance of tea tortrix populations especially during wet weather as well as during dry weather can be attributed to the increased levels of hyperparasitism as shown in this study.

As Macrocentrus exhibits polyembryony (a single egg breakdown into many eggs which results in as many adult parasites) the effect of parasites and therefore, the parasitism is accumulative where a parasitized tortrix larva gives rise to many parasites, which parasitize many tortrix larvae again. When parasites are affected by hyperparasites and hence, the parasitism, the cumulative effect of parasites would be reduced. The natural balance between the host, the tortrix and the parasite, is disrupted, resulting in appearance of large numbers of tortrix larvae.

Tea tortrix infestations resulted in a measurable damage and therefore, control of populations in any location and weather is critical [14]. Insect growth regulators (IGR's) and Chitin synthesis inhibitors (CSI's) have been used against tea tortrix until recently but, the use of IGR which was very effective against tea tortrix was discontinued as a result of its non-compliance with Maximum Residue Level (MRL) stipulated by the major tea buyers [15]. On the other hand, growers are reluctant to use CSI due high cost of application. Despite the high cost, CSI can be used if pockets of infestations are treated at the correct time based on sampling for life stages of tea tortrix. This is only possible if tortrix infestations are noticed during the dry periods but chemical treatment is not advocated during the wet periods because of the wash out of chemical. Therefore, when tortrix numbers are picked up in wet periods then cultural methods would be resorted into by the growers in these tea plantations.

One of the methods that growers can employ to reduce the tea tortrix population is to maintain the regular plucking rounds depending on the labour availability. Plucking of tea takes place at 7 days intervals but, it's being delayed due to shortage of labour in most of these plantations. If regular plucking rounds can be maintained during wet periods then plucking will removes most of the tortrix larvae which will greatly reduce the damage to tea. A recent study has showed that collection of tortrix egg masses to be an economical way of reducing the impacts of tortrix generations especially during the wet weather [14]. If the plantations can train the field staff including the tea pluckers/harvesters on how to pick up egg masses while on their usual plucking rounds tortrix damage can be greatly reduced. It can be concluded that under this reduced parasitism (biological control) and the limitations on the use of chemical control methods, tortrix problem can be tackled by cultural practices for example, collecting tea tortrix egg masses.

\section{Acknowledgements}

The author appreciates the help given by the Managers, Assistant Managers and Filed Officers of Sheen, Duncinan, Fernlands and Eildon Hall Estates. Special thanks are due to Mr. Chula De Alwis, Manager, Duncinan Estate for his enthusiasm and help on this work at his estate during the study. Technical Officers of the Ento mology Division, Chandima De Seram and Muditha Jayathilake involved in the sampling which is greatly acknowledged. The author also gratefully thank Ms. Rasika Priyanjalie, the Laboratory Assistant of the Entomol- 
ogy Division, for sorting out field samples painfully and record the data throughout the course of this study on which this publication is based on.

\section{References}

[1] Cranham, J.E. (1966) Monographs on Tea Production in Ceylon No. 6 Insects and Mite Pests of Tea in Ceylon and Their Control. The Tea Research Institute of Ceylon, Talawakelle, Ceylon, 27 p.

[2] Cranham, J.E. (1961) The Natural Balance of Pests and Parasites on Ceylon Tea, Especially Tortrix and Macrocentrus. Tea Quart, 32, 26-41.

[3] Gadd, C.H. (1946) Macrocentrus homonae, a Polyembrayonic Parasite of Tea Tortrix, Homona coffearia Nietn. Ceylon Journal of Science (B), 23, 67-79.

[4] King, C.B.R. (1939) Report of the Entomologist. TRI Bulletin, 18, 28-34.

[5] Norris, R.V. (1939) Diseases and Pests of Tea. Tea Quart, 12, 7-8.

[6] Danthanarayana, W. (1971) Report of the Entomology Division. TRI Annual Report for 1969, 175-181.

[7] Vitarana, S.I. (1989) An Eco Taxonomic Key for Identification of Tea Pests in the Field (Insects and Mites). Tea Bulletin, 9, 3-45.

[8] Vitarana, S.I. (1994) Report of the Entomologist. TRI Annual Report, 54-67.

[9] Gadd, C.H. (1940) Report of the Mycologist. TRI Bulletin, 22, 32-38.

[10] Gadd, C.H. (1949) Report of the Mycologist. TRI Bulletin, 30, 27-67.

[11] SAS Institute (2011) SAS User's Manual. Version 9.3 Edition, SAS Institute.

[12] Amarasinghe, L.D., Vitarana, S.I. and Abeysekera, A.R. (2002) Current Status of the Parasitism and Hyperparasitism of Tea Tortrix (Homona coffearia, Nietner) and Their Influence on the Population Stability in Sri Lanka. Journal of Plantation Crops, 30, 64-65.

[13] Vitarana, S.I., Walgama, R.S., Abeysekera, A.R., Dharmalatha, R.D.P. and Jayathilake, M.M. (2000) Hyperparasitism of Tea Ortrix. Proceedings of the Annual Sessions of the Institute of Biology of Sri Lanka, Colombo, August 2000, 15.

[14] Walgama, R.S., Nandakuamara, S., De Seram, C., Randeniya, S. and Sannasooriya, R. (2009) A Simple and Cost Effective Way Out for Managing Tea Tortrix in Plantations: A Case Study. Proceedings of the 219th Experiment and Extension Forum, Tea Research Institute of Sri Lanka, July 2009, 42-47.

[15] Walgama, R.S, Jayathilaka, M.M., De Seram, C. and Jayakody, J.A.A.M. (2008) Managing Tea Tortrix under Present Day Scenario. Proceedings of the 217th Experiment and Extension Forum, Tea Research Institute of Sri Lanka, July 2008, 56-63. 